\title{
Doğu Kayını (Fagus orientalis Lipsky.) Bireylerinde Farklı Alana Geliş Şekillerine Göre Bazı Morfolojik ve Fizyolojik Özellikler Arasındaki Farklılıkların İncelenmesi
}

\author{
Halil Barış ÖZEL ${ }^{1 *}$, Hakan ŞEVİK ${ }^{2}$, Sinan KAPTAN, ${ }^{1}$ Tuğrul VAROL ${ }^{1}$ \\ ${ }^{1}$ Bartın Üniversitesi, Bartın Orman Fakültesi, Orman Mühendisliği Bölümü, 74100, Bartın \\ ${ }^{2}$ KastamonuÜniversitesi, Mühendislik ve Mimarlık Fakültesi, Çevre Mühendisliği, 37210, Kastamonu
}

\section{Öz}

Doğu kayını (Fagus orientalis Lipsky), ülkemiz ormanlarının asli ağaç türlerinden birisi olan yaklaşık 1,9 milyon ha yayılış alanı ile toplam ülke ormanlarımızın yaklaşık \%8,5'ini oluşturmaktadır. Bu çalışma kapsamında, tohum ve sürgün kökenli doğu kayını bireylerinde bazı morfolojik ve fizyolojik karakterlerin alana gelişş şekline ve yükseltiye bağlı olarak değişiminin belirlenmesi amaçlanmıştır. Çalışma kapsamında üç farklı yükselti kademesinde bireyler üzerinde boy, kök boğazı çapı, fotosentez, stomal iletkenlik, transpirasyon ve toplam taze ağırlığı ölçümleri yapılmıştır. Çalışma sonucunda sürgün kökenli bireylerde elde edilen değerlerin diğerlerine göre nispeten daha yüksek düzeyde olduğu ancak, yükseltinin karakterler üzerine çok daha etkili olduğu, bütün karakterlerde en yüksek değerlerin düşük yükseltilerde elde edildiği ve yükselti arttıkça değerlerin düştüğü belirlenmiştir.

Anahtar Kelimeler: Doğu Kayını, morfoloji, fizyoloji, yükselti.

\section{Investigation of the Differences Among Some Morphological and Physiological Characteristics According to the Ways of Development in Oriental Beech (Fagus orientalis Lipsky.) Individuals}

\begin{abstract}
Oriental beech (Fagus orientalis Lipsky), which is one of the main tree species of our country's forests, constitutes approximately $8.5 \%$ of total country forests, with a distribution area of approximately 1.9 million hectares. Within the scope of this study, it was aimed to determine the change of some morphological and physiological characters in seed-origin and sprout-origin oriental beech individuals depending on the way of arrival and altitude. Within the scope of the study, height, root collar diameter, photosynthesis, stomal conductivity, transpiration and total fresh weight measurements were made on individuals at three different elevation levels. As a result of the study, it was determined that the values obtained in individuals with sprout-origin were relatively higher than the others, but the altitude was much more effective on the characters, the highest values were obtained in all characters at low altitudes, and the values decreased as the altitude increased.
\end{abstract}

Keywords: Oriental beech, morphology, physiology, altitude.

\footnotetext{
*Sorumlu Yazar (Corresponding Author):

Halil Barış ÖZEL (Prof. Dr.); Bartın Üniversitesi, Orman Fakültesi, Orman

Geliş (Received) : 28.06.2021

Mühendisliği Bölümü, Ağdacı Kampüsü, 74100, Bartın-Türkiye. Tel: +90 (378) 223

Kabul (Accepted) : 09.08.2021

5153, Fax: +90 (378) 223 5062, E-mail: halil@bartin.edu.tr

Basım (Published) : 15.08.2021

ORCID: 0000-0001-9518-3281
} 


\section{Giriş}

Genel coğrafi yayılışııı Doğu Balkan Yarımadası (Bulgaristan, Romanya, Yunanistan), Kırım, Kafkasya, Kuzey İran'da yapan doğu kayını (Fagus orientalis Lipsky), ülkemizde Kırklareli, Balıkesir, İstanbul, Bursa, Sakarya, Kastamonu, Amasya, Tokat, Giresun, Artvin, Kütahya, Eskişehir, Adana, Hatay'da yapraklı ya da karışık ormanlarda (30-) 700-1.200 (-2.000) m'ler arasında yapmaktadır. 40 m'ye kadar boylanabilen, önemli orman ağacı türlerimizdendir (Yılmaz, 2018). Ülkemiz ormanlarının asli ağaç türlerinden birisi olan doğu kayını 1.630.196 hektarı normal kapalı olmak üzere toplam 1.899.929 hektarlık yayılış alanı ile meşe türlerinden sonra en fazla yayılış gösteren ikinci yapraklı türdür. Doğu kayınının bu yayılış alanı ile toplam ülke ormanlarımız içerisindeki payı yaklaşık \%8,5’tir (Demirel, 2019).

Türkiye'deki Kayın ormanlarının büyük bölümünün antropojen etkiler ve işletme hataları nedeniyle sürgün kökenli bireylerden oluştuğu belirtilmektedir (Yılmaz, 2006). Vejetatif olarak sürgünden oluşan bireylerin genç yaştan itibaren dipten çürümeye başladığı, odun kalitesinin olumsuz yönde etkilendiği ayrıca, eski kuşaklarla aynı genetik yapıya sahip olduğu, bu durumun da genetik tabanın daralmasına neden olduğu ve genetik yenilenmeyi engellediği belirtilmektedir (Yılmaz vd., 2009). Genetik çeşitlilik, gelecekte olması muhtemel, bugünden tahmin edilemeyen risklere karşı en önemli savunma mekanizmasıdır. Bundan dolayı özellikle doğal popülasyonlarda genetik çeşitlilik büyük önem taşımaktadır (Sevik vd., 2010).

Bitkilerin bütün morfolojik, anatomik, fizyolojik ve fenolojik karakterleri genetik yapı (Yigit vd., 2016; Yucedag vd., 2019; Ozel vd., 2020) ile çevre şartlarının (Sevik vd., 2019a,b;) etkisi altında şekillenmektedir. Bitkilerin kökenleri genetik yapıyı önemli ölçüde şekillendirirken, yükselti de çevre şartlarında önemli değişikliklere sebep olmaktadır. Yükselti, en önemli iklimsel parametrelerden sıcaklığı büyük oranda etkilemekte (Ertugrul vd., 2021; Kilicoglu vd., 2021), bundan dolayı da bitkilerin optimum yayılış alanları, yükseltinin etkisi altında şekillenmektedir (Esen ve Avcı, 2020; Ning vd., 2021). Bu çalışma kapsamında, farklı yükseltilerden temin edilen tohum kökenli ve sürgün kökenli doğu kayını (Fagus orientalis Lipsky) fidanlarında bazı morfolojik ve fizyolojik karakterlerin köken ve yükseltiye bağlı olarak değişiminin belirlenmesi amaçlanmıştır.

\section{Materyal ve Metot}

Çalışma doğu kayını (Fagus orientalis Lipsky) fidanları üzerinde gerçekleştirilmiştir. Araştırma alanı Yenice Orman İşletme Müdürlüğü'nün, Kızılkaya Orman İşletme Şefliği sınırları içerisinde yer almakta olup $982 \mathrm{~m}$ yükseltide ve kuzeydoğu bakıdadır. Arazi orta yamaçta olup, toprak kumlu-killi-balçık tekstüründedir. Toprak organik maddece zengin ve derin toprak koşulları hakim olup, granular strüktür yapısına sahiptir. Çalışma kapsamında 5 yaşındaki bireyler üzerinde boy (BOY), kök boğazı çapı (KBC), fotosentez (FOT), stomal iletkenlik (STIL), transpirasyon (TRA) ve toplam taze ağırlık (TAZEAG) ölçümleri yapıllmıştır. Ölçümler sabah 9:30-10:30 arasında gerçekleştirilmiştir. Her yükselti kademesinde ölçümler bir günde bu saat diliminde tamamlanmıştır.

Elde edilen veriler SPSS 22.0 paket programı yardımıyla değerlendirilmiş, verilere varyans analizi ve Duncan testi uygulanmıştır. Böylece ölçülen karakterlerin yükselti ve köken bakımından farklılıkları istatistiki olarak belirlenmeye çalışılmıştır. Ayrıca veriler arasındaki ilişki düzeyini belirleyebilmek amacıyla verilere korelasyon analizi uygulanmıştır.

\section{Bulgular}

Çalışmaya konu karakterlerin yükselti ve köken bazında ortalama değerleri ile varyans analizi sonucunda elde edilen F değerleri ve Duncan testi sonucunda oluşan gruplaşmalar Tablo 1'de verilmiştir.

Varyans analizi sonucunda çalışmaya konu bütün karakterlerin hem tohum kökenli bireylerde (F değeri1) hem de sürgün kökenli bireylerde ( $F$ değeri2) yükseltiye bağlı olarak değişimi istatistiki olarak \%99,9 güven düzeyinde anlamlı bulunmuştur. Duncan testi sonucunda bütün karakterlerde üç homojen grup oluşmuş en düşük değerlerin elde edildiği 800-1.200 m yükselti aralığ 1 ilk grubu oluştururken en yüksek değerlerin elde edildiği 400-600 m yükselti aralığı son grubu oluşturmuş̧ur. Bütün yükselti aralıkları toplu olarak değerlendirildiğinde (F değeri3) yine bütün karakterler bakımından yükselti aralıklarının $\% 99,9$ güven düzeyinde anlamlı olmak üzere farklılaştığı belirlenmiştir. Yapılan Duncan testi sonucunda genel olarak en düşük değerler (tohum kökenli bireyler daha düşük olmak üzere) 800-1.200 m yükseltide, en yüksek değerler ise (sürgün kökenli bireyler daha yüksek olmak üzere) 400-600 m yükseltilerde elde edilmiş̧ir. 
Tablo 1. Karakterlerin yükselti ve köken bazında değişimi.

\begin{tabular}{|c|c|c|c|c|c|c|}
\hline $\begin{array}{l}\text { Yükselti } \\
\text { (m) }\end{array}$ & $\begin{array}{l}\text { BOY } \\
(\mathrm{cm})\end{array}$ & $\begin{array}{l}\text { KBC } \\
(\mathbf{m m})\end{array}$ & $\begin{array}{l}\text { FOT } \\
\left(\mu \mathrm{mol} \mathrm{m} \mathrm{m}^{-2} \mathrm{~s}^{-1}\right)\end{array}$ & $\begin{array}{l}\text { STIL } \\
\left(\mathrm{cm} \mathrm{s}^{-1}\right)\end{array}$ & $\begin{array}{l}\text { TRA } \\
\left(\mu g \mathrm{~cm}^{-2} \mathrm{~s}^{-1}\right)\end{array}$ & $\begin{array}{l}\text { TAZEAG } \\
\text { (gr) }\end{array}$ \\
\hline $400-600$ & 68,47 cC & 8,75 bC & $16,20 \mathrm{eC}$ & $8,82 \mathrm{cB}$ & 8,67 cdC & $132,58 \mathrm{cC}$ \\
\hline $600-800$ & $53,67 \mathrm{bB}$ & $6,36 \mathrm{aB}$ & $13,23 \mathrm{cB}$ & $8,09 \mathrm{cB}$ & $6,80 \mathrm{bB}$ & $115,13 \mathrm{bB}$ \\
\hline $800-1.200$ & $42,96 \mathrm{aA}$ & 5,06 aA & 8,80 aA & 5,99 aA & 5,49 aA & 93,74 aA \\
\hline F Değeri1 & $22,324 * * *$ & $19,585^{* * *}$ & $94,502 * * *$ & $18,308 * * *$ & $25,383 * * *$ & $37,914 * * *$ \\
\hline $400-600$ & $78,97 \mathrm{dC}$ & 11,56 cC & $14,89 \mathrm{dC}$ & $10,85 \mathrm{dC}$ & $9,27 \mathrm{dC}$ & $149,05 \mathrm{dC}$ \\
\hline $600-800$ & $68,56 \mathrm{cB}$ & 9,27 bB & $11,28 \mathrm{bB}$ & $8,95 \mathrm{cB}$ & $8,23 \mathrm{cB}$ & $131,62 \mathrm{cB}$ \\
\hline $800-1.200$ & $51,80 \mathrm{bA}$ & 6,15 aA & $8,08 \mathrm{aA}$ & $7,00 \mathrm{bA}$ & 6,36 bA & $100,93 \mathrm{aA}$ \\
\hline F Değeri2 & $45,161 * * *$ & $26,680 * * *$ & $99,494 * * *$ & $51,128 * * *$ & $29,346 * * *$ & $74,160 * * *$ \\
\hline F Değeri3 & $31,249 * * *$ & $25,905 * * *$ & $81,379 * * *$ & $29,969 * * *$ & $24,860 * * *$ & $49,211 * * *$ \\
\hline F Değeri4 & $11,161^{* *}$ & $13,167 * *$ & $2,637 \mathrm{~ns}$ & $8,716^{* *}$ & $5,735^{*}$ & $6,414^{*}$ \\
\hline
\end{tabular}

F Değeri1: Tohum kökenli bireylerde yükseltilar arası farkl1lıklara ilişkin F değeri

F Değeri2: Sürgün kökenli bireylerde yükseltilar arası farklılıklara ilişkin F değeri

F Değeri3: Bütün bireylerde köken ve yükseltilar arası farklılıklara ilișkin F değeri

F Değeri4: Farklı kökenli bireylerde kökenler arası farklı1ıklara ilişkin F değeri

a, b, c: Duncan testi sonucuna göre (hem sürgün hem de tohum kökenli bireyler içerisinde) değerlerin yer aldığı grupları göstermektedir.

A, B, C: Duncan testi sonucuna göre (sadece sürgün kökenli ya da tohum kökenli bireyler içerisinde) değerlerin yer aldığı grupları göstermektedir.

Tohum ve sürgün kökenli bireyler arasında istatistiki olarak anlamlı düzeyde $(\mathrm{p}<0,05)$ fark olup olmadığını belirleyebilmek için yapılan varyans analizi sonucunda (F değeri4) farklı kökenli bireyler arasında fotosentez aktivitesi bakımından istatistiki olarak en az \%95 güven düzeyinde fark bulunmadı̆̆ı, transprasyon ve taze ağırlık değerleri bakımından \%95, diğer karakterler bakımından ise \%99 güven düzeyinde anlamlı farklılıklar bulunduğu belirlenmiştir. Bu sonuçlara göre çalışmaya konu karakterler üzerine yükseltinin etkisinin kökenin etkisinden daha yüksek düzeyde olduğu söylenebilir. Yükselti arttıkça bütün değerlerin azaldığı belirlenmiş̧ir.

Çalışmaya konu karakterler arasında istatistiki olarak bir ilişkinin bulunup bulunmadığını belirleyebilmek amacıyla verilere korelasyon analizi uygulanmış ve sonuçlar Tablo 2'de verilmiştir.

Tablo 2. Korelasyon analizi sonuçları.

\begin{tabular}{|c|c|c|c|c|c|c|}
\hline & BOY & KBC & FOT & STIL & TRA & TAZEAG \\
\hline Yükselti & $-0,757^{* *}$ & $-0,704^{* *}$ & $-0,912^{* *}$ & $-0,758^{* *}$ & $-0,772^{* *}$ & $-0,837^{* *}$ \\
\hline BOY & & $0,961^{* *}$ & $0,770^{* *}$ & $0,964^{* *}$ & $0,980^{* *}$ & $0,969^{* *}$ \\
\hline KBC & & & $0,710^{* *}$ & $0,931^{* *}$ & $0,939^{* *}$ & $0,944^{* *}$ \\
\hline FOT & & & & $0,786^{* *}$ & $0,815^{* *}$ & $0,831^{* *}$ \\
\hline STIL & & & & & $0,944^{* *}$ & $0,960^{* *}$ \\
\hline TRA & & & & & & $0,957^{* *}$ \\
\hline
\end{tabular}

Karakterler arasındaki ilişkiler incelendiğinde bütün karakterler arasında istatistiki olarak anlamlı düzeyde $(p<0,01)$ ilişki bulunduğu görülmektedir. Bu ilişki bütün karakterler arasında kuvvetli olup, yükselti ile bütün karakterler arasındaki ilişkiler negatif yönlüdür. Diğer bütün karakterler ise birbirleriyle pozitif yönlü ilişki içerisindedir.

\section{Sonuç ve Tartışma}

Çalışma sonuçları fotosentez dışındaki bütün karakterlerde sürgün kökenli bireylerde elde edilen değerler ile tohum kökenli bireylerde elde edilen değerler arasında istatistiki olarak anlamlı düzeyde $(\mathrm{p}<0,05)$ farkl1lıklar bulunduğunu ve sürgün kökenli bireylerde elde edilen değerlerin daha yüksek düzeyde olduğunu ortaya koymaktadır. 
Gardiner (1998) meşede yaptığı bir çalışmada, tohum kökenli ve sürgün kökenli bireyleri karşılaştırmış ve tohum kökenli bireylerin boyu başlangıçta $38,8 \mathrm{~cm}$ iken çalışma sonucunda $79,5 \mathrm{~cm}$ olarak ölçülmüş, sürgün kökenli bireylerde de başlangıçta $38,8 \mathrm{~cm}$ olan boy çalışma sonucunda $91,2 \mathrm{~cm}$ olarak ölçülmüştür. Benzer şekilde kök boğazı çapı da çalışma süresince tohum kökenli bireylerde 5,4 mm'den 11,4 mm'ye, sürgün kökenli bireylerde de 5,8 mm'den 11,8 mm'ye çıkmıştır. Aynı çalışmada tohum kökenli bireylerde fotosentez hızı daha yüksek düzeyde ölçülürken, stomatal iletkenlik, transprasyon ve özsu akışı sürgün kökenli bireylerde daha yüksek düzeyde belirlenmiștir. Ancak varyans analizi sonucunda bu karakterlerin hiç birisinde tohum kökenli ve sürgün kökenli bireyler arasında istatistiki olarak anlamlı düzeyde fark bulunmadığı belirlenmiştir (Gardiner, 1998).

Çalışma sonucunda bütün karakterlerin yükseltiye bağlı olarak önemli ölçüde değisstiği, bütün karakterlerde en yüksek değerlerin düşük yükseltilerde elde edildiği ve yükselti arttıkça değerlerin düştüğü belirlenmiştir. Bugüne kadar yapılan çok sayıda çalışmada fidan morfolojik özellikleri ile yükselti ve orijin arasındaki ilişki ortaya konulmuş̧tur (Gülseven vd., 2019). Orijinin etkisinin, yükseltinin etkisinden daha etkili olabildiğini gösteren çalışmalar mevcuttur. Gülseven vd., (2019) $510 \mathrm{~m}$ ile $1.515 \mathrm{~m}$ ortalama yükseltiye sahip kayın populasyonlarını karşılaştırdıkları çalışma sonucunda Akçasu $(850 \mathrm{~m})$ ile Tefen $(750 \mathrm{~m})$ populasyonlarına ait fidanların gerek morfolojik gerekse fizyolojik karakterler bakımından en yüksek değerlere sahip olduğu tespit etmişlerdir. Buna karşın İnegöl (1.000 m), Dursunbey (1.515) ve Çatalzeytin (700) populasyonlarında ise özellikle morfolojik karakterler bakımından daha düşük değerler elde edilmiştir. Bu sonuçlar genetik yapının bitki gelişimini şekillendiren önemli bir faktör olduğunu ortaya koymaktadır ki bugüne kadar yapılan çalışmalarda da canlı karakterlerini ve gelişimini etkileyen en önemli faktörlerden birisinin genetik yapı olduğu ortaya konulmuştur (Sevik vd., 2012; Hrivnák vd., 2017).

Ancak yine de yükselti bitki karakterlerini ve gelişimini etkileyen en önemli faktörlerdendir. Çünkü canlıların bütün fenotipik karakterleri genetik yapıları (Cetin vd., 2020; Cesur vd., 2021) ile çevre koşullarının (Ertuğrul vd., 2014; Varol vd., 2019) etkileşimine bağlı olarak şekillenmektedir ve yükselti arttıkça sıcaklık ve yağış koşulları gibi iklim özellikleri de değişmektedir (Esen ve Avc1, 2020; Yucedag vd., 2021). Bitki gelişimini etkileyen çevre koşulları arasında en önemli faktörlerin başında iklim parametreleri (Yigit vd., 2019; Koc, 2021) özellikle de sıcaklık ve yağış gelmektedir (Ertugrul vd., 2019; Sevik vd., 2021). Aynı enlemde bulunan farklı yükseklikteki alanlarda deniz seviyesinden yükseğe çıkıldıkça her 100 m'de sıcaklık kuru havada $1^{\circ} \mathrm{C}$, nemli havada $0.6{ }^{\circ} \mathrm{C}$ düşmektedir. Yüksek alanlarda gece ile gündüz arasındaki sıcaklık farkları daha yüksektir. Ilıman iklim kuşağında yükseltinin artması sonucu atmosfer sıcaklığı azalmakta ve yağış miktarı artmaktadır (Cüce vd., 2020). Bundan dolayı da yükselti bitki örtüsünün karakterinde belirleyici faktörlerdendir (Esen ve Avcı, 2020).

Ağaçlandırma çalışmalarında başarı, her şeyden önce kaliteli tohum ve fidan kullanımına bağlıdır (Özel vd., 2021). Doğu kayını ormanlarının \%63,7'sinin yapısının bozulmuş olduğu ve yeniden verimli hale getirilmesinin gerektiği belirtilmektedir (Özel vd., 2015). Dolayısıyla bu alanların rehabilite edilebilmesi için kaliteli fidanlara ihtiyaç duyulmaktadır ve bundan dolayı da kaliteli fidan üretmek için öncelikle kaliteli fidan kaynaklarını tespit etmek, fidan kalitesini etkileyen faktörleri belirlemek büyük önem taşımaktadır. Çalışma sonuçları sürgün kökenli bireylerin tohum kökenli bireylerden daha iyi gelişim gösterdiğini ortaya koymakla birlikte bu farkın nispeten düşük seviyede olduğu belirlenmiştir. Sürgün kökenli bireylerin genç yaşlarda tohum kökenli bireylerden daha hızlı büyüdüğü ancak, ileri yaşlarda bu üstünlüğün, tohum kökenli bireyler lehinde değiştiği belirtilmektedir (Asan, 1990). Bundan dolayı genetik çeşitlilik faktörü de dikkate alınarak ağaçlandırmalarda tohum kökenli fidan kullanılması önerilmektedir.

Bununla birlikte çalışma sonuçları düşük yükseltilerden temin edilen fidanların daha yüksek performans gösterdiğini ortaya koymaktadır. Ayrıca yapılan çalışmalar küresel iklim değişikliğine bağlı olarak türler için uygun yayılış alanlarının yüksek yükseltilara doğru kayacağını göstermektedir (Varol vd., 2021). Ayrıca küresel iklim değişikliği sürecinde kuraklık gibi stres faktörlerinin artacağı belirtilmektedir (Ozel vd., 2021a,b; Cetin, 2020; Koç, 2021). Bundan dolayı da özellikle büyük tohumlu türlerin yüksek yükseltilara doğru göç etmesinde insan desteğine ihtiyaç duyacağı vurgulanmaktadır (Gomez-Pineda vd., (2020). Bütün bu faktörler göz önünde bulundurularak kayın ağaçlandırmalarında düşük yükseltilerden alınan orijinlerin daha yüksek yükseltilerdeki ağaçlandırma çalışmalarında kullanılması önerilebilir.

\section{Kaynaklar}

1. Asan, Ü. (1990). Sürgün kökenli kayın ormanlarında bonitet araştırmaları. İstanbul Üniversitesi Orman Fakültesi Dergisi, 40(2), 70-90.

2. Cesur A., Zeren Cetin I., Abo Aisha A. E. S., Alrabiti O. B. M., Aljama A. M. O., Jawed A. A., Cetin M., Sevik H., Ozel H. B. (2021). The usability of Cupressus arizonica annual rings in monitoring the 
changes in heavy metal concentration in air. Environmental Science and Pollution Research (Environ Sci Pout Res) 2021. https://doi.org/10.1007/s11356-021-13166-4

3. Cetin, M. (2020). The Changing of Important Factors in The Landscape Planning Occur Due to Global Climate Change in Temperature, Rain and Climate Types: A Case Study of Mersin City. Turkish Journal of Agriculture-Food Science and Technology. 8(12): 2695-2701

4. Cetin, M., Sevik, H., Cobanoglu, O. (2020). Ca, $\mathrm{Cu}$, and $\mathrm{Li}$ in washed and unwashed specimens of needles, bark, and branches of the blue spruce (Picea pungens) in the city of Ankara. Environmental Science and Pollution Research, 27(17), 21816-21825.

5. Cüce, H., Kalıpcı, E., Taş, B., Yılmaz, M. (2020). Yükselti farklılı̆̆ı nedeniyle oluşan meteorolojik değişimlerin su kalitesine olan etkilerinin CBS ile değerlendirilmesi: Morfolojik olarak farklı iki göl için bir karşılaştırma. Karadeniz Fen Bilimleri Dergisi, 10(1), 1-26. https://doi.org/10.31466/kfbd.649297

6. Demirel, H. (2019). Bartın-Kumluca Yöresi Saf Doğu Kayını (Fagus orientalis Lipsky.) Doğal Gençleştirme Alanlarında Meşcere Kuruluşları ve Gençlik Dinamiklerinin İncelenmesi. Bartın Üniversitesi Fen Bilimleri Enstitüsü Orman Mühendisliği Anabilim Dalı Yüksek Lisans Tezi, 28 s.

7. Ertuğrul, M., Varol, T., Özel, H. B. (2014). Climate changes in prospect for the West Black Sea Forests. Bartın Orman Fakültesi Dergisi, 16(23), 35-43.

8. Ertugrul, M., Ozel, H. B., Varol, T., Cetin, M., Sevik, H. (2019). Investigation of the relationship between burned areas and climate factors in large forest fires in the Canakkale region. Environmental Monitoring and Assessment, 191 (12), 737.

9. Ertugrul, M., Varol, T., Ozel, H. B., Cetin, M., Sevik, H. (2021). Influence of climatic factor of changes in forest fire danger and fire season length in Turkey. Environmental Monitoring and Assessment, 193(1), 1-17.

10. Esen, F., Avcı, V. (2020). Berit Dağları'nda (Kahramanmaraş) litolojik ve jeomorfolojik faktörlerin bitki örtüsünün dağılışına etkisi. Gaziantep Üniversitesi Sosyal Bilimler Dergisi, 19(3): 664-685.

11. Gardiner, E. S. (1998). Water relations and morphology of Nuttall oak seedling sprouts. In Proceedings of the ninth biennial southern silvicultural research conference. Gen. Tech. Rep. SRS-20. Asheville, NC: US Department of Agriculture, Forest Service, Southern Research Station: 284-288.

12. Gómez-Pineda, E., Sáenz-Romero, C., Ortega-Rodríguez, J. M., Blanco-García, A., MadrigalSánchez, X., Lindig-Cisneros, R., ..., Rehfeldt, G. E. (2020). Suitable climatic habitat changes for Mexican conifers along altitudinal gradients under climatic change scenarios. Ecological Applications, 30(2), e02041.

13. Gülseven, O., Ayan, S., Özel, H. B., Yer, E. N., (2019). Farklı doğu kayını (Fagus orientalis Lipsky.) populasyonlarına ait fidanların morfolojik ve fizyolojik karakteristikleri. Turkish Journal of Forestry, 20(3): 180-186.

14. Hrivnák, M., Paule, L., Krajmerová, D., Kulaç, Ş., Şevik, H., Turna, İ., Tvauri, I. Gömöry, D. (2017). Genetic variation in Tertiary relics: The case of Eastern-Mediterranean Abies (Pinaceae). Ecology and Evolution, 7(23), 10018-10030.

15. Kilicoglu, C., Cetin, M., Aricak, B., Sevik, H. (2021). Integrating multicriteria decision-making analysis for a GIS-based settlement area in the district of Atakum, Samsun, Turkey. Theoretical and Applied Climatology, 143(1), 379-388.

16. Koc, I. (2021). Using Cedrus atlantica's annual rings as a biomonitor in observing the changes of $\mathrm{Ni}$ and Co concentrations in the atmosphere. Environmental Science and Pollution Research, https://doi.org/10.1007/s11356-021-13272-3

17. Koç, I. (2021). Examining Seed germination rate and seedlings gas exchange performances of some Turkish Red Pine provenances under water stress. Düzce Üniversitesi Bilim ve Teknoloji Dergisi, 9(3), 4860.

18. Ning, H., Ling, L., Sun, X., Kang, X., Chen, H. (2021). Predicting the future redistribution of Chinese white pine (Pinus armandii Franch). Under climate change scenarios in China using species distribution models. Global Ecology and Conservation, 25, e01420.

19.Ozel HB, Cetin M, Sevik H, Varol T, Isik B, Yaman B (2021a) The effects of base station as an electromagnetic radiation source on flower and cone yield and germination percentage in Pinus brutia Ten. Biologia Futura (2021). https://doi.org/10.1007/s42977-021-00085-1

20.Ozel, H. B., Donduran, B., Cakmakli, E., Sevik, H. (2020). Factors affecting success in natural regeneration works of cedar (Cedrus libani A. Rich.) In Kas region of Antalya. World Journal of Advanced Research and Reviews, 6(2), 054-059.

21. Ozel, H. B., Abo Aisha, A. E. S., Cetin, M. Sevik, H., Zeren Cetin, I. (2021b). The effects of increased exposure time to UV-B radiation on germination and seedling development of Anatolian black pine seeds. Environmental Monitoring and Assessment 193, 388. https://doi.org/10.1007/s10661-021-09178-9 
22. Özel, H. B., Kirdar, E., Bilir, N. (2015). The effects of magnetic field on germination of the seeds of oriental beech (Fagus orientalis Lipsky.) and growth of seedlings. Agriculture \& Forestry/Poljoprivreda $i$ Sumarstvo, 61(3): 195-206.

23. Özel, H. B., Palta, Ş., Çakmaklı, E. (2021). Arbusküler mikorizal fungus aşılamasının doğu kayını (Fagus orientalis Lipsky.) fidanlarının büyüme performansı ve adaptasyon başarısı üzerine etkilerinin araştırılması. Bartın Orman Fakültesi Dergisi, 23(1), 217-225.

24. Sevik, H., Ayan, S., Turna, I., Yahyaoglu, Z. (2010). Genetic diversity among populations in Scotch pine (Pinus sylvestris L.) seed stands of Western. African Journal of Biotechnology, 9(43), 266-7272.

25. Sevik, H., Yahyaoglu, Z., Turna, I. (2012). Determination of genetic variation between populations of Abies nordmanniana subsp. bornmulleriana Mattf according to some seed characteristics, genetic diversity in plants. Chapter, 12, 231-248.

26. Sevik, H., Cetin, M., Ozturk, A., Ozel, H. B., Pinar, B. (2019a). Changes in Pb, Cr and Cu concentrations in some bioindicators depending on traffic density on the basis of species and organs. Applied Ecology and Environmental Research, 17(6), 12843-12857.

27. Sevik, H., Cetin, M., Ozturk, A., Yigit, N., Karakus, O. (2019b). Changes in micromorphological characters of Platanus orientalis L. leaves in Turkey. Applied Ecology and Environmental Research, 17(3), 5909-5921.

28. Sevik, H., Cetin, M., Ozel, H. B., Erbek, A., Cetin, I. Z. (2021). The effect of climate on leaf micromorphological characteristics in some broad-leaved species. Environment, Development and Sustainability, 23(4), 6395-6407.

29. Varol, T., Gormus, S., Cengiz, S., Ozel, H. B., Cetin, M. (2019). Determining potential planting areas in urban regions. Environmental Monitoring and Assessment, 191(3), 1-14.

30. Varol, T., Canturk, U., Cetin, M., Ozel, H. B., Sevik, H. (2021). Impacts of climate change scenarios on European ash tree (Fraxinus excelsior L.) in Turkey. Forest Ecology and Management. Forest Ecology and Management 491(2021) 119199. https://doi.org/10.1016/j.foreco.2021.119199

31. Yılmaz, M. (2006). Doğu kayını (Fagus orientalis Lipsky) tohumlarında ekim öncesi işlemler. Orman Mühendisliği Dergisi, 27-30.

32. Yılmaz, M., Tonguç, F., Çetin, B. (2009). Doğu Akdeniz bölgesindeki sürgün kökenli kayın ormanlarının gençleşme sorunları. Bartın Orman Fakültesi Dergisi, Özel, (2), 633-639.

33. Yılmaz, H. (2018). Fagus L. (Kayınlar). (Ed. Ü. Akkemik) Türkiye'nin Doğal-Egzotik Ağaç ve Çalıları. Orman Genel Müdürlüğ̈̈ Yayınları, Ankara. s: 337-338.

34. Yigit, N., Sevik, H., Cetin, M., Gul, L. (2016). Clonal variation in chemical wood characteristics in Hanönü (Kastamonu) Günlüburun black pine (Pinus nigra Arnold. subsp. pallasiana (Lamb.) Holmboe) seed orchard. Journal of Sustainable Forestry, 35(7), 515-526.

35. Yigit, N., Cetin, M., Ozturk, A., Sevik, H., Cetin, S. (2019). Varitation of Stomatal Characteristics in Broad Leaved Species Based on Habitat. Applied Ecology and Environmental Research, 17(6):1285912868.

36. Yucedag, C., Cetin, M., Ozel, H. B., Aisha, A. E. S. A., Alrabiti, O. B. M., Jama, A. M. O. A. (2021). The impacts of altitude and seed pretreatments on seedling emergence of Syrian juniper (Juniperus drupacea (Labill.) Ant. et Kotschy). Ecological Processes, 10(1), 1-6.

37. Yucedag, C., Ozel, H. B., Cetin, M., Sevik, H. (2019). Variability in morphological traits of seedlings from five Euonymus japonicus cultivars. Environmental Monitoring and Assessment, 191(5), 1-4.

38. Zeren Cetin, I., Ozel, H. B., Varol, T. (2020). Integrating of settlement area in urban and forest area of Bartin with climatic condition decision for managements. Air Quality, Atmosphere \& Health, 13(8), 10131022. 